\title{
Current key options for management of industrial alkaline waste of alumina production (red mud)
}

\author{
Htet Ye Aung ${ }^{1}$, Alexander Boyarintsev ${ }^{1, *}$, Sergey Stepanov ${ }^{1}$, and Andrei Shoustikov ${ }^{1}$ \\ ${ }^{1}$ Mendeleev University of Chemical Technology, 9, Miusskaya square, 125047, Moscow, Russia
}

\begin{abstract}
Due to the ever-increasing demand of the world economy for aluminum, its alloys and compounds, the production of this metal is increasing annually throughout the world. This leads to an increase in the industrial production of alumina, which is obtained from bauxite ore in the Bayer process. After recovering the bulk of the aluminum from the bauxite ore, there remains a residue which is highly alkaline toxic waste, which is also called bauxite residues (tailings) or red mud (RM). About 140-150 million tons of RM are produced annually and almost 4 billion tons have already been accumulated. At the moment, the problem of RM recycling and the development of effective and cost-effective approaches to their reprocessing is extremely urgent. Reducing RM affects economic, environmental, social areas and is a prerequisite for the sustainable development of nature and society. Despite active scientific research and efforts to develop and optimize various methods for RM recycling and reprocessing, the problem of an annual increase in their volumes around the world remains unresolved. Recently, promising and efficient processes have been proposed that allows for the complex reprocessing of RM with the extraction of a number of valuable liquid products that may be in demand in various fields of industry. This allows to focus on large-scale disposal of RM and can be a solution to the problem of handling these industrial wastes. The article considers the main current trends in the field of management of various types of RM with a focus on complex reprocessing and zero waste concepts.
\end{abstract}

\section{Introduction}

In the modern practice of existing alumina plants due to the lack of complex reprocessing and large-scale effective utilization, the bulk of RM is located in specially equipped landfill sites, which are tailing ponds or stacks. At the same time, large areas of land become polluted and removed from agricultural circulation, as well as serious environmental problems arise as a result of the negative impact of toxic components of RM on all natural ecosystems and humans $[1,2]$

At the moment, about 4 billion tons of RM have been accumulated in the world and this number is constantly increasing every year. It should also be noted that the problem of RM

*Corresponding author: aboyarincev@muctr.ru 
accumulation can be partially solved by improving the reprocessing of the raw bauxite feedstock as a whole in order to reduce waste generation.

In the absence of efficient reprocessing of RM and their placement for long-term storage, there is a loss of all valuable metals, many of which are contained in economically significant quantities in these facilities. Therefore, RM can be considered as a valuable potential secondary polymetallic feedstock and a source of valuable metals such as iron $(\mathrm{Fe})$, aluminum $(\mathrm{Al})$, titanium $(\mathrm{Ti})$, vanadium $(\mathrm{V})$, niobium $(\mathrm{Nb})$, zirconium $(\mathrm{Zr})$, gallium $(\mathrm{Ga})$, and especially the most valuable and expensive rare earth elements (REEs): scandium (Sc), yttrium (Y), lanthanum (La), lanthanides (Ln). REEs have many applications and are often considered as indispensable components in high-tech and green technologies. They are critical metals with a high supply risk and their demand increases annually. The extraction of these metals seems very important for the development of the rare earth industry, so their extraction from RM can solve the problem of providing a raw material base in many countries. RM can be also considered as promising raw materials base for the production of building materials.

RM's current storage and disposal methods do not fully address environmental concerns arising from toxic components of these man-made wastes. Large-scale alumina production puts great pressure on the infrastructure of RM storage sites for alumina plants, and the financial costs of maintaining RM sludge storage in safe conditions and hosting RM are high. Modern practice should include rehabilitation of exhausted RM landfill storage sites. They can be used for both industrial and civilian purposes, should be decontaminated and re-afforested in order to recreate a habitable place for plants and animals.

$\mathrm{RM}$ reprocessing management is usually based on strategies related to disposal, neutralization, utilization, partial or complex reprocessing (Fig. 1). Management and storage of RM, as a rule, depend on: age of the alumina plants, land availability or proximity to sea, existence of local features such, as the old developed mines, climate, logistics, the nature of the residue and local regulations [3].

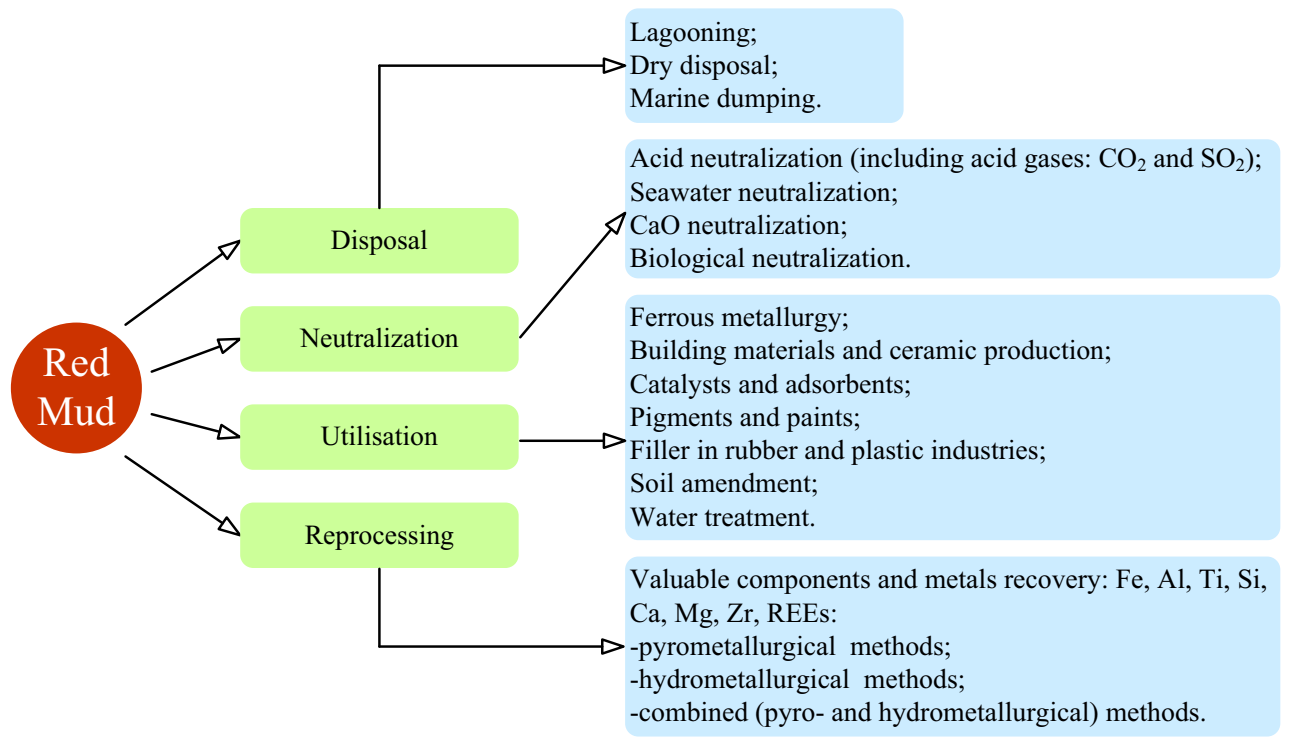

Fig. 1. Strategies for management of red mud.

The development of suitable efficient RM recycling or reprocessing method is important for its mass use, increased profitability and transition to the concept of zerowaste valorisation. [4-7]. This concept assumes that all industrial resources are in some way 
used in the final product or are converted into value-added raw materials for other industries or processes.

\section{Disposal of red mud}

For RM disposal, marine dumping, lagooning, dry stacking or dry disposal methods are used. If RM is discharged into deep sea, sea water is contaminated with toxic components, harmful metals and metalloids: $\mathrm{As}, \mathrm{Pb}, \mathrm{Hg}, \mathrm{Cd}, \mathrm{Cr}, \mathrm{Ni}, \mathrm{Mo}$, V, etc.; radioactive elements: ${ }^{238} \mathrm{U},{ }^{232} \mathrm{Th}$ and their decay products; as well as fine and colloidal particles such as aluminum and magnesium compounds, leading to an increase in turbidity of the sea [8]. In the case of lagooning, alkaline $(\mathrm{pH} \sim 10-13) \mathrm{RM}$ slurry is directly pumped into specially equipped ground-based filler sludge ponds. The main problems and negative consequences of storing the RM slurry are (i) expensive maintenance of large areas of sludge ponds; (ii) high $\mathrm{pH}$ alkali toxicity for all living organisms; (iii) leakage of alkaline compounds into ground water and leaching of harmful metals and metalloids from RM; (iv) overflow of toxic materials and dusting of dry surfaces of RM with large content of fine particles generation interferes with rehabilitation of plant life; (v) natural radioactivity [9]. The dry storage method reduces the area of valuable land resources for placing RM, but at the same time there is a problem of dust formation, and additional means are required for the operation of special equipment (for example, filtration plants) [10]. Currently, the most common methods of placing RM are dry disposal and lagooning. Despite of the use of advanced techniques and the proper safe storage of RM, the risk of accident on a dam and emergence of ecological disaster always remains [11]. The only way to reduce the potential threat and associated environmental damage is to stop storing and accumulating RM at tailings ponds and begin their large-scale reprocessing.

\section{Neutralization of red mud}

Neutralization is necessary for conversion of toxic alkaline components in RM composition into less dangerous low-alkaline forms, for example, into sodium bicarbonate $(\mathrm{pH}=8.5$ 8.9), which makes RM suspension safer for environment under conditions of long-term storage [12]. This allows to significantly reduce the impact of RM on the environment and offers new opportunities for the use of both freshly generated and landfilled RM. Neutralization of $\mathrm{RM}$ to $\mathrm{pH} \sim 8.0$ is most optimal, since all chemically adsorbed sodium is released, alkaline buffer minerals are neutralized, and many toxic metals are insoluble at this $\mathrm{pH}$ value [10].

Various types of RM treatment are used to reduce its $\mathrm{pH}$, using mineral acids [13], treatment with gaseous or liquid carbon dioxide [14], neutralization with sea water enriched with calcium and magnesium brines, and some other methods [15].

\section{Utilization of red mud}

Due to its unique physicochemical properties, RM can be used in many fields. At the moment, a large number of patents have been proposed where various options for the possible use and applications of RM are considered. Among the main fields of RM use which were used in pilot or commercial scale are: (i) ferrous metallurgy (additive for agglomeration, domain melting of iron ores, raw materials for receiving iron, slag-forming reagent for refinement of cast iron and steel, partial substitute of clays at production of casting molds); (ii) a component (filler) in the manufacture of ceramic articles (tiles, floor tiles), concrete, cement (including special cements), building materials (bricks), refractory 
materials; (iii) as filler in the rubber and plastic industries; (iv) as pigment in production of paints; (v) in road construction (mostly of the coarse fraction); (vi) as a feedstock for manufacturing adsorbents and catalysts; (vii) as feedstock for reagents used in water treatment and wastewater treatment processes; (viii) as a material used to capture harmful acid-forming gases such as carbon dioxide and/or sulfur dioxide in flue gases; (ix) for amendment of acidic soils, for immobilization of heavy metals and/or for retention of certain nutrients, such as phosphorus in agriculture and in other areas [16,17] All RM applications listed are of limited use. The use of RM in the production of building materials may be limited due to the increased content of radioactive elements.

\section{Partial and complex reprocessing of red mud}

$\mathrm{RM}$ is difficult-to-process feedstock. The complex RM reprocessing is further complicated by the large diversity of each type of RM. As a rule, the chemical and mineralogical composition of RM depends on the composition of the processed bauxite ore, the type of process and the condition of its implementation (temperature, pressure, presence of chemical additives). The difficulty of RM reprocessing is also due to the fine particle size and extremely high alkalinity [18].

Currently, a large number of technological schemes have been proposed that allow for both partial and complex reprocessing of RM with the production of a number of separate useful products. Pyro- and hydrometallurgical methods are used to process of RM (Fig. 2). Complex reprocessing of RM is mainly based on a combination of these methods. This makes it possible to involve almost all RM components in the processing and significantly reduce the amount of waste. However, combining pyro- and hydrometallurgical methods can cause difficulties in implementing combined process schemes on the basis of one production site [19]. It should be noted that current trends suggest cleaner and ecologically safe reprocessing. When developing new processes, it is also necessary to take into account the principles of reducing the number of technological stages.

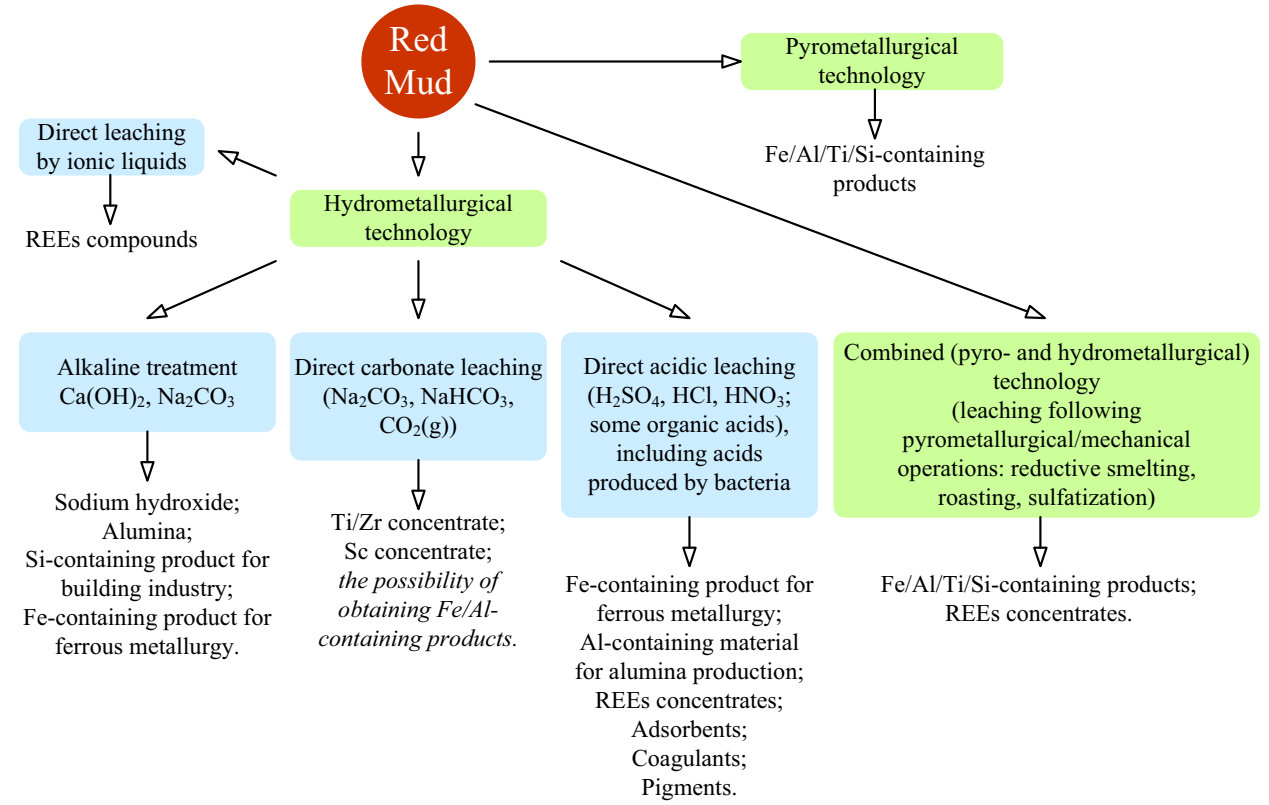

Fig. 2. Red mud reprocessing options. 


\subsection{Pyrometallurgical reprocessing of red mud}

Pyrometallurgical methods in RM reprocessing technology are mainly used to extract certain components that form the basis of RM: Fe, Al, Ti, and Si. Iron oxide, which is the main component of RM, can be recovered by reductive smelting with carbon normally used as the reducing agent. That is done by reduction melting and reduction burning of RM in furnaces of boiling bed or in furnaces of shaft type. After these processes, products containing iron concentrate, titanium and alumina are obtained [20,21].

\subsection{Hydrometallurgical reprocessing of red mud}

In hydrometallurgical method RM is processed to extract valuable components, mainly aqueous solutions of mineral acids (sulfuric, hydrochloric, and nitric) [22-24], as well as some organic acids (acetic, citric, and methanesulfonic acids) [25,26]. On the basis of mineral acid solutions, options for the selective extraction of REEs from RM have been developed. It is also proposed to use ionic liquids [27] and bioleaching processes [28] to extract REEs from RM. As alternative reagents for selective extraction of $\mathrm{Sc}, \mathrm{Zr}$ and some other valuable metals from RM, aqueous solutions of $\mathrm{Na}_{2} \mathrm{CO}_{3}, \mathrm{NaHCO}_{3}$ or their mixtures are proposed. Scientific foundations of carbonate processes of Sc extraction from RM were developed by employees of ISSC RAS UB (Russia) [28] and subsequently developed by some researchers [29-33].

The use of acids provides a high degree and ease of extraction of REEs from all types of $\mathrm{RM}$ due to the high content of compounds $\mathrm{Fe}, \mathrm{Al}, \mathrm{Ca}$ and $\mathrm{Ti}$, which are relatively easily decompose in acidic solutions releasing valuable components. At the same time, acids have high corrosive activity for equipment materials and lead to the formation of multicomponent salt solutions, which are difficult to process and utilize.

The use of carbonate reagents and the carrying out of the leaching process under carbonization conditions (under excessive pressure or bubbling $\mathrm{CO}_{2}(\mathrm{~g})$ ) also allows the selective extraction of $\mathrm{Sc}, \mathrm{Zr}, \mathrm{Ti}, \mathrm{Ga}$ and other valuable metals from certain types of $\mathrm{RM}$ (for example, Russian RM) [28]. To increase the extraction of the target components into carbonate solutions, the use of physical intensification methods (mechanical activation, ultrasound, vibro-cavitation effect) is proposed [29,34,35]. Recovery of target components from RM in carbonate media is lower compared to acid methods. However, the advantage of carbonate media is (i) reduced corrosion activity; (ii) the possibility of improving environmental safety through regeneration of carbonate salts and organization of recycling of solutions into the process cycle, (iii) as well as reduction of salt products which create difficulties for separation and selective extraction of target components. The use of gas carbonation using $\mathrm{CO}_{2}$-containing industrial gases allows to reduce $\mathrm{SO}_{2}$ emissions to some extent and reduce air pollution. Use of carbonate media for RM reprocessing allows to use some versions of equipment and technological lines of active alumina production without significant modification [28].

In hydrometallurgical approaches of RM reprocessing, as a rule, other RM components are leached together with REEs, including radioactive elements that form soluble stable compounds in both acidic and carbonate media. Therefore, in some cases, further reprocessing of the technological solutions requires their deactivation.

Alkaline methods of RM reprocessing are mainly including extraction of alumina and alkali. For the regeneration of alkali $(\mathrm{NaOH})$, various options can be implemented, the main of which is treatment of $\mathrm{RM}$ with lime milk $\left(\mathrm{Ca}(\mathrm{OH})_{2}\right)$. In order to reduce alumina losses (as a part of hydrogarnet), a small amount of $\mathrm{Na}_{2} \mathrm{CO}_{3}[36,37]$ is introduced together with lime. 


\subsection{Complex reprocessing of red mud}

When considering the most developed areas of RM reprocessing, we should mention complex reprocessing with production of alumina, cast iron and cement at sites of alumina plants, as well as obtaining transportable RM for shipment and further reprocessing of new commercial products at other operating enterprises [38].

Complex reprocessing of RM with the release of chemical and metallurgical products is an important reserve for increasing production efficiency, both in the direction of rational use of raw materials and preservation of the habitat. Two key factors determine the relevance of studies aimed at complex RM reprocessing. The first is related to costeffectiveness and completeness of recovery of the most valuable micro components, mainly REEs, Ga, $\mathrm{Zr}$ compounds, and conversion of macro components ( $\mathrm{Fe}, \mathrm{Al}, \mathrm{Si}, \mathrm{Ca}, \mathrm{Mg}$ ) into valuable products. The second factor is reducing the amount of RM discharged into the environment, removing historically accumulated reserves, and solving environmental problems associated with RM placement in tailing ponds.

Separation of $\mathrm{Fe}, \mathrm{Al}$ and $\mathrm{Ti}$ from $\mathrm{RM}$ in the form of materials suitable for ferrous or non-ferrous metallurgy, and the use of Si-containing residue in the production of building materials stipulate the development of a complex reprocessing scheme with a near-zerowaste flow [39]. However, other RM reprocessing schemes are possible. For example, REEs may be removed from slag which is formed during removing iron in the form of cast iron. Associated extraction of expensive and critical REEs (Sc, Y, La, and Ln) allows increasing the cost-effectiveness of the technology, expanding the raw material base of these valuable metals and reducing the risks of their supply. Recovery of REEs from RM can be performed at pre-treatment stage consisting of leaching of REEs from RM with further reprocessing of remaining residue for extraction of other metals [40]. In work [41], it is proposed to obtain alloyed cast iron, as well as rich Ti and REEs slag during blast furnace smelting of iron and titanium enriched RM. In [42], a method of deep reprocessing of RM is proposed to produce cast iron and porous amorphous aluminosilicate material of stable chemical composition concentrating of rare-earth oxides. Work [43] presents the results of the study of complex reprocessing of bauxite and RM according to the scheme, which includes reduction melting to produce cast iron and slag based on calcium aluminates enriched by REEs, as well as sequential extraction of aluminum oxide, titanium and concentrate of REEs oxides. In work [44], the slag containing REEs is leached by soda after pyrometallurgical reprocessing of RM to extract aluminum, and insoluble residue containing calcium oxide and REEs oxides is processed in aqueous solutions of hydrochloric acid with further extraction of REEs concentrate.

\section{Conclusions}

Due to the significant efforts of researchers over the years, a large number of various strategies have been developed for the disposal or reprocessing of RM. However, to date, there is no economically viable and environmentally sound solution for efficient large-scale RM recycling. Therefore, most of the generated RM continues to be stored and accumulated on the ground for future rehabilitation or use. At the same time, only complex reprocessing of RM using technology combining pyro- and hydrometallurgical processes, can allow for the disposal of all toxic components of RM and turn this waste into very valuable and useful products. 


\section{Acknowledgements}

The research was supported by Mendeleev University of Chemical Technology. Project № T-2020-009. Measurements (studies) were made on the equipment of the Center for Collective Use of Mendeleev University of Chemical Technology.

\section{References}

1. K. Deelwal, Int. J. Adv. Eng. Tech. 7(3), 1053-1059 (2014)

2. P.K.N. Raghavan, N.K. Kshatriya, K. Wawrynink, Light Metals (Springer, 2011)

3. M.S. Keamou, A.M.F. Rashid, J.M. Saedi, Z. Zaki, J. Eng. Sci. Tech. SU18, 120-134 (2019)

4. K. Sanjay, K. Rakesh, A. Bandopadhyay, Resources, Conservation and Recycling 48, 301-314 (2006)

5. K. Binnemans, P.T. Jones, B. Blanpain, T.V. Gerven, Y. Pontikes, Journal of Cleaner Production 99, 17-38 (2015)

6. S. Stopić, C. Dertmann, B. Xakalashe, G. Alkan, B. Yagmurlu, H. Lucas, B. Friedrich, XXI YuCorr Conference (Tara Mountain, Serbia, 2019)

7. P.J. Joyce, Doctoral thesis (KTH Royal Institute of Technology, Stockholm, 2018)

8. S. Patel, B.K. Pal, IJLTEMAS 4, 8, 1-16 (2015)

9. R.C. Sahu, R.K. Patel, B.C. Ray, J. Hazard. Mater. 179, 1-3, 28-34 (2010)

10. S. Rai, K.L. Wasewar, J. Mukhopadhyay, K.Y. Chang, H. Uslu, Arch. Environ. Sci. 6, 13-33 (2012)

11. É. Ujaczki, V. Feigl, M. Molnár, P. Cusack, T. Curtin, R. Courtney, L. O’Donoghue, P. Davris, C. Hugi, M. WH Evangelou, E. Balomenos, M. Lenzh, J. Chem Technol Biotechnol 93, 2498-2510 (2018)

12. S. Rai, K.L. Wasewar, D.H. Lataye, R.S. Mishra, S.P. Puttewar, J.M. Chaddha, P. Mahindiran, J. Mukhopadhyay, Waste Management \& Research 30, 9, 922-930 (2012)

13. S.B. Rai, K.L. Wasewar, R.S. Mishra, S.P. Puttewar, M.J. Chaddha, J. Mukhopadhyay, K.Y. Chang, Res. J. Chem. Environ. 17, 7, 10-17 (2013)

14. E. Szirmai, S. Babusek, G. Balogh, A. Nedves, G. Horvath, Z. Lebenyi, J. Pinter, Patent 5053144 (1991)

15. J.S. Palmer, M. Nothling, K. Bakon, R. Frost, Journal of Colloid and Interface Science 342, 1, 147-154 (2010)

16. A.I. Ivanov, G.N. Kozhennikov, F.G. Sitdikov, L.P. Ivanova, Complex processing of bauxite (URO RAS, Yekaterinburg Russia. 2013)

17. Y. Hannachi, N.A. Shapovalov, A. Hannachi, Korean J. Chem. Eng. 27, 152-158 (2010)

18. K.A. Staley, Ph.D Thesis (Golden, CO: Colorado School of Mines, 2002)

19. V.A. Lipin, Non-ferrous metals, 6, 42-45 (2006)

20. N.A. Vatolin, Patent of France № 1336621 (1963)

21. L.A. Smirnov, Y.V. Sorokin, N.M. Snyatinovskaya, N.I. Danilov, A.Yu. Eremin, Processing of man-made wastes (LLC UIPC, Yekaterinburg, Russia. 2012)

22. K. Hatzilyberis, T. Lymperopoulou, L.A. Tsakanika, K.M. Ochsenkühn, P. Georgiou, N. Defteraios, F. Tropelas, M. Ochsenkühn-Petropulu, Minerals 8, 3 (2018) 
23. R.M. Rivera, B. Ulenaers, G. Ounoughene, K. Binnemans, T.V. Gerven, Min. Eng. 119 (2018)

24. C.R. Borra, Y. Pontikes, K. Binnemans, T.V. Gerven, Min. Eng. 76 (2015)

25. E. Ujaczki, Y. Zimmermann, V. Feigl, M. Lenz, Proceedings of Bauxite Residue Valorisation and Best Practices Conference (Leuven, Belgium, 2015)

26. P. Davris, E. Balomenos, D. Panias, I. Paspliaris, Rare earths industry (Elsevier, Amsterdam. 2016)

27. Y. Qu, H. Li, W. Tian, X. Wang, X. Wang, X. Jia, B. Shi, G. Song, Y. Tang, Miner Eng. 81, 1-4 (2015)

28. N.A. Sabirzyanov, S.P. Yatsenko, Hydrochemical methods of complex processing of bauxite (URO RAS, Yekaterinburg, Russia, 2006)

29. V. Rychkov, M. Botalov, E. Kirillov, S. Kirillov, V. Semenishchev, G. Bunkov, D. Smyshlyaev, Hydromet. 199, 105524 (2021)

30. O.V. Petrakova, A.V. Panov, S.N. Gorbachev, G.N. Klimentenok, A.V. Perestoronin, S.E. Vishnyackov, V.S. Anashkin, Light Metals (Springer, 2015)

31. A. Suss, N.V. Kuznetsova, A. Kozyrev, A. Panov, S. Gorbachev, $35^{\text {th }}$ International ICSOBA Conference (Hamburg, Germany, 2017)

32. A.V. Boyarintsev, M.M. Aung, H.Y. Aung, S.I. Stepanov, Vestnik VGUIT 80, 3 (2018)

33. S.I. Stepanov, M.M. Aung, H.Y. Aung, A.V. Boyarintsev, Vestnik VGUIT 80, 4 (2018)

34. G.N. Klimentenok, V.S. Anashkin, S.E. Vishnyakov, A.V. Panov, Patent RU2536714 (2014)

35. I.R. Boboev, P.V. Alexandrov, V.A. Imidiev, Patent RU2630183 (2017)

36. K. Solymar, J. Steiner, L. Huszar, Femip. Kat. Int. Kozlemen. 7, 47-64 (1964)

37. V.Y. Miller, A.I. Ivanov, Non-ferrous metals 2, 145-148 (1963)

38. V.A. Utkov, V.M. Sizyakov, Zapiski Gornogo instituta 202, 39-43 (2013)

39. C.R. Borra, B. Blanpain, Y. Pontikes, K. Binnemans, T.V. Gerven, Critical Materials 16, 343-356 (2019)

40. L. Piga, F. Pochetti, L. Stoppa, Miner. Met. Mater. Soc. 45, 54-59 (1993)

41. I.V. Loginova, V.A. Lebedev, S.F. Gordon, A.V. Kyrchikov, Non-ferrous metals 7, 4548 (2010)

42. M.V. Pavlov, I.V. Pavlov, V.F. Pavlov, O.V. Shabanova, V.F. Shabanov, Proceedings of the All-Russian Conference on Rare Earth Materials (Tomsk, Russia, 2013)

43. N.A. Vatolin, Chemistry in the interests of sustainable development 1, 337-346 (1993)

44. E.A. Korshunov, S.P. Burkin, Y.N. Loginov, I.V. Loginova, E.A. Andriukova, V.S. Tretyakov, Patent RU2245371 (2005) 